\title{
A PRESENÇA DA MULHER NA MAGISTRATURA DO ESTADO DE GOIÁS
}

\author{
WOMEN'S PRESENCE IN THE JUDICIARY OF GOIÁS
}

\author{
Christiane de Holanda Camilo ${ }^{1}$
}

\section{RESUMO}

O presente artigo realiza uma análise quali-quantitativa sobre o fenômeno da feminização no âmbito do Poder Judiciário Estadual do Estado de Goiás, especificamente observando este fenômeno quanto a presença de magistradas no exercício da função de juízas nas diferentes entrâncias segundo os critérios de acesso, promoção e remoção.

Palavras-chave: Feminização; Direito; Magistratura;

\section{ABSTRACT}

This paper makes a qualitative and quantitative analysis of the feminization of the phenomenon in the State Judiciary of the State of Goiás, specifically observing this phenomenon for the presence of magistrates in the exercise of judges function in different indentation according to access criteria, promotion and removal.

Keywords: Feminization; Law; Magistracy;

\footnotetext{
1. Doutoranda em Sociologia pela Universidade Federal de Goiás - UFG, Goiás (Brasil). Professora da Universidade do Tocantins-UNITINS. E-mail: christianedeholanda@ gmail.com
} 


\section{INTRODUÇÃO}

A presença na mulher em diferentes espaços de trabalho e profissões é uma realidade em expansão. Este artigo visualizará se ocorre também o fenômeno da feminização em uma área do conhecimento e cargo tradicionalmente ocupados por homens.

O Direito como um dos cursos universitários mais antigos do país ao lado da Medicina, tradicionalmente foi ocupado por homens desde essa época, contudo, visto que nas décadas de 1980 e 1990 houve grande expansão do trabalho exercido por mulheres, há a possibilidade dessa área ter passado por uma transformação com igual ampliação da presença da mulher. (BONELLI, 2008)

Dentre uma das carreiras jurídicas mais tradicionais encontra-se a magistratura estadual, que devido à envergadura dos conhecimentos necessários ao exercício da função e à própria organização da progressão na carreira, tornar-se magistrado demanda tempo. E em razão do exposto no parágrafo anterior, nessa profissão, a presença de homens era mais comum que a de mulheres, situação quem em tese não se justificaria atualmente tendo em vista o aumento do número de mulheres nas universidades, bem como, nos cursos de Direito no Brasil nas últimas décadas do século XX.

Para a exposição e análise do assunto o artigo será dividido em duas partes, a primeira expondo sobre o fenômeno da feminização e o segundo, uma análise quantiqualitativa da composição do Tribunal de Justiça do Estado de Goiás quanto a presença e a localização das mulheres que ocupam a função de juízas, situação que segue uma hierarquização por meio de entrâncias e funções exercidas.

\section{O campo, afeminização e o telhado de vidro.}

Para analisar se o fenômeno da fenimização é uma realidade da carreira da magistratura do Poder Judiciário do Estado de Goiás serão problematizadas aqui quatro discussões situando a compreensão de gênero (SCOTT, 1995; DAVIS, 1975; PISCITELLI, 2002,2009) utilizada na pesquisa, a compreensão do fenômeno da feminização das carreiras jurídicas (BONELLI, 2008, 2013; SADECK, 2006; BRUSCHINI, 2000, BARBALHO, 2008) e as trajetórias de construção de carreira (GUIMARÃES \& GEORGES, 2009), e ainda as discussões sobre campo, habitus e capital social para Bourdieu (2001)para contextualizar os 
elementos do capital social dos indivíduos, os círculos sociais que reforçam a sociabilidade e a dominação masculina, bem como, a consideração sobre as barreiras invisíveis que impedem o acesso da mulher ao espaços hierárquicos de poder dentro das instituições, conhecidas como “telhado de vidro", "glassceiling”. (GROVER, 2015)

Ao estudar a trajetória de trabalhadores em funções de gerência em São Paulo Nadya Guimarães e Isabel Georges inserem a relevância qualitativa das perspectivas subjetivas sobre a construção de carreiras profissionais. As autoras observaram importantes fatores que interferem na carreira e na transição da carreira, ou seja, nas trajetórias profissionais. Esses podem ser correlacionados a diferentes setores profissionais, e dizem respeito a condicionantes tais como "posição social, condição de gênero e raça, e posição no ciclo de vida", bem como, observar que padrões masculinos e femininos na construção das carreiras profissionais possuem diferentes valores e significados para cada gênero, assim, para homens e mulheres, as representações que fazem sobre família e outras relações sociais, tornam-se decisivas nas opções de carreira, frequentemente transformando o "curso provável" de uma carreira, no "curso efetivo" resultante das ações da pessoa no mundo do trabalho. (GUIMARÃES \& GEORGES, 2009)

Todavia, há que se considerar toda uma estrutura construída socialmente que atua sobre instituições e pessoas continuamente. Portanto, as carreiras profissionais efetivamente percorridas pelos diferentes profissionais, não são apenas resultado de decisões individuais, além delas, as instituições sociais historicamente constroem perfis profissionais desejados para a atuação em cada segmento profissional.

Os perfis profissionais histórica, cultural e socialmente elaborados se entrecruzam de forma corrente sobre os indivíduos conforme as diferentes construções conceituais que estabelecem os variados "scripts" sociais relacionados a gênero, raça, religião, nível social, formação, nível de conhecimento, etc., que por sua vez, devem se adequar ao perfil desejado.

Gênero é apenas um desses aspectos que constituem e caracterizam perfis profissionais.

Scott (1995) desconecta-se da primeva conceituação dicotômica (BOURDIEU, 2001) oubinária da diferenciação sexual entre homens e mulheres concentrando-se em uma caracterização de gênero que define à forma de organização social entre os sexos, explorando o que os papéis sexuais simbolicamente representam na sociedade para organizá-la e lhe conferir sentido. (SCOTT, 1995, apud.DAVIS,1975) 
Portanto, não se trata de reduzir gênero a uma "questão feminina", ou a um dualismo infrutífero de forças, competências ou habilidades entre homens e mulheres, e sim, dentro dos limites observáveis dessa pesquisa, ao observar a distribuição de gênero na estrutura política do Estado,a visualização da presença da mulher(PISCITELLI, 2002, 2009) no Poder Judiciáriopermite visualizar como sociedade até o momento inscreve a mulher nesse pilar da estrutura tripartite do poder estatal. Como resultado de igual medida, observar o número de homens e mulheres e a posição ocupada por eles na estrutura do Poder Judiciário,essa pesquisa permite visualizar, quantificar, descrever e analisar os espaços políticos ocupados por homens e mulheres dentro da estrutura judiciária do Estado de Goiás.

Devido ao tipo de pesquisa adotada por esse estudo, a pesquisaquali-quantitativa de caráter bibliográfico-documental, utilizou os dados disponibilizados pelo próprio Tribunal de Justiça do Estado de Goiás em seu site oficial até quinze de julho de 2015, visto que é de notória responsabilidade do Poder Público a transparência e publicidade de seu atos.

Assim, de forma sintética as categorias interrelacionadas nessa pesquisa relacionam gênero em sentido estrito ou binário estruturado na divisão entre homens e mulheres, relacionando-o à identificação da presença da mulher, ou ao fenômeno da feminização,em determinada categoria profissional, a magistratura, exercida no âmbito do Poder Judiciário do Estado de Goiás.

O exercício da magistratura permite considerar que o perfil historicamente construído dessa categoria profissional no Brasil constituiu-se a princípio, como tradicionalmente masculino, visto que o curso de Direito foi um dos primeiros cursos a ser ofertado no país, desde 1828 (NASPOLINI, 2008) e, desde então, houve grande presença de homens nesse curso. Todavia, como apontado por Bonelli (2008, 2013),Sadek (2006) e Barbalho (2008) há uma tendência de feminização das carreiras jurídicas, contudo, Bruschini (2000) mesmo reconhecendo esta tendência,junto com o próprio Censo do Conselho Nacional de Justiça (2014) afirmam que a magistratura ainda permanece essencialmente constituída por homens no Brasil.

Para compreender como operam os sistemas simbólicos de poder em relação ao gênero pode-se compreendê-lo a partir de Bourdieu (2001). Na obra Poder Simbólico, Pierre Bourdieu (2001) busca explicar como os atores sociais internalizam a estrutura social, como a produzem, reproduzem e legitimam segundo a realização do que o autor denomina como a economia das trocas simbólicas que colocam em jogo a disputa por diferentes tipos de capitais, simbólico, social e cultural e ainda pelo domínio da violência simbólica. 
Para tanto, Bourdieu (2001) se propõe a fazer uma análise pela pesquisa em ação da teoria científica revelada pelo trabalho empírico.

Bourdieu faz a defesa da ciência como forma laboriosa a mostrar o pensamento e a teoria, um modo de operação orientadora e organizadora da prática científica. (BOURDIEU, 2001)

Contudo, segundo o autor, a ciência, ao estabelecer a persecução à todo custo da originalidade, pode frequentemente incorrer em ignorância ou fidelidade negligente e quase religiosa a determinados autores, comportamento esse totalmente antagônico à proposição inicial de Bourdieu (2001) em defesa da tradição teórica que deve se conduzir por continuidades, rupturas, conservações e superações teóricas. O trabalho de construção conceitual é uma atividade histórica e cumulativa. (BOURDIEU, 2001)

O desafio do cientista é realizar o pensamento produtivo, ou seja, "produzir ativamente os melhores produtos dos pensadores do passado pondo a funcionar os instrumentos de produção que eles deixaram". (BOURDIEU, 2001, p. 63)

Assim como uma música que contém os princípios da composição, o texto quanto à sua capacidade de elaboração do pensamento, seria uma composição teórica que conduzissem o cientista (agente) à prática e poderia ser posta como a concepção de um intelectual engajado. (BOURDIEU, 2001)

O conceito de habitus exprime a recusa a toda uma série de alternativas nas quais a ciência social fronteiriza-se com a subjetividade, com o inconsciente entre outros. Bourdieu recorreu à noção de habitus como uma forma racional de orientar-se no espaço, uma forma de totalização, em determinada prática todo um conjunto de saberes. (BOURDIEU, 2001)

A história é inscrita nos corpos por meio do habitus, o habitus recorre a uma estrutura de segunda natureza orientada por certa autonomia condicionada pela história e pelo meio em que está localizado, pois, é um conceito que mostra-se a princípio como infraconsciente, um conhecimento sem consciência, ou ainda, de uma intencionalidade sem intenção declarada que ganha autonomia pela ação dos agentes por meio da aprendizagem, contudo, apresentam-se mais como norteadores ou bases que podem seguir o que a princípios seus autores haviam estabelecido ou percorrer trajetórias totalmente diversas de forma explícita ou implícita de acordo com a autonomia dos agentes que tomaram contato com ele. (BOURDIEU, 2001) 
Em sentido similar Bourdieu elaborou a noção de campo, primeiro como um direcionamento da pesquisa e, depois, no duplo exercício de teorização e relação com a realidade histórica. $\mathrm{O}$ autor contextualiza a sua discussão exemplificando-a no campo da arte buscando compreender a criação social de um campo bem como as crenças que o sustentam em um verdadeiro processo de depuração. (BOURDIEU, 2001)

A teoria geral dos campos permite perceber a estrutura das relações entre diferentes capitais, e, com ela, descrever formas específicas, que traduzem o que é cada campo, sua estrutura mecanismos e conceitos, um sistema de posições. (BOURDIEU, 2001)

Esse processo permite perceber como se estabelece a origem social de um campo. Importante por proporcionar a afirmação da autonomia do campo de produção cultural que concomitantemente se cria e se auto-reforça. Para Bourdieu o analista investiga a ação objetiva inscrita no que é declarado, o que corresponde a pulsão expressiva. (BOURDIEU, 2001)

A constituição do campo parte de se considerar que o campo é fruto da produção simbólica entre os agentes que buscam impor a categorização de sua visão, divisão e compreensão do mundo social, dessa forma o campo é sempre um campo político, um campo de disputas, um campo de poder simbólico que classifica e estabelece pertencimentos e valores. Contudo, os símbolos apenas se afirmam por meio da prática, da prática dos agentes (habitus) que reafirmam a posição e o valor do símbolo dentro do sistema e assim, em seu conjunto colaboram para a integração social, e, por conseguinte, a possibilidade de reprodução da ordem social estabelecida, das representações, das dominações. (BOURDIEU, 2001)

Teoria dos campos de Bourdieu aplicada aos estudos sobre a competição profissional, ao observar que o campo registra a pretensão de ser algo, um espaço onde as posições ocupadas pelos agentes se encontram previamente estabelecidas, torna-se, por essa razão, um espaço de disputas entre esses agentes.

Assim, se observarmos a área de conhecimento, Bruschini $(2007,1994)$ afirma que no Brasil em 2005 as mulheres chegaram a se constituir em 62\% das formandas.

Todavia, o estudo nos mostra que elas procuram preferencialmente áreas do conhecimento conhecidas como sendo tradicionalmente femininas, constituindo "guetos ocupacionais femininos" quando manifesta-sea concentração de mulheres em determinadas áreas de conhecimento e em outras não. (BRUSCHINI, 2007) 
A autora ressalta que $81 \%$ das mulheres se concentra na Educação, Artes e Humanidades correspondem a uma presença de 65\%, na área de Saúde e bem-estar socialperfazem $74 \%$, todavia, minoritariamente são encontradas em áreas da Ciências Sociais, Negócios e Direito (54\%), isto não levando em consideração áreas como a de Ciências Matemáticas e Computação(39,1\%), ou ainda, Engenharia, produção e computação onde a presença da mulher é menor ainda (29,5\%). (BRUSCHINI, 2007)

Se assim colocarmos no espaço da magistratura homem e mulher em tese estão em um espaço de disputa e possuem papéis previamente estabelecidos de acordo com o “capital social” de cada gênero. As escolhas de cada gênero são guiadas e condicionadas pela posição de cada gênero no campo de acordo com o sistema de estratificação estruturado desigualmente em relação ao capital social que aqui ressaltamos a possibilidade de se aplicar tanto ao gênero, bem como, particularmente a cada pessoa.

O capital social do indivíduo é

o conjunto de recursos atuais ou potenciais que estão ligados à posse de uma rede durável de relações mais ou menos institucionalizadas de interconhecimento e de inter-reconhecimento ou, em outros termos, à vinculação a um grupo, como conjunto de agentes que não somente são dotados de propriedades comuns (passíveis de serem percebidas pelo observador, pelos outros ou por eles mesmos) (BOURDIEU, 2003, p. 67),

Portanto, "os benefícios angariados por virtude da pertença a um grupo são a própria base em que assenta a solidariedade que os torna possíveis" (BOURDIEU, 1985, p. 249).

A definição de capital social de Bourdieu(2001) clarifica que o capital social é constituído por duas características, ambas qualitativas e quantitativas simultaneamente: a primeira diz respeito as relações sociais que permitem aos indivíduos reivindicarem acesso aos recursos que estão em posse dos membros de um grupo, bem como, a segunda, que referese a quantidade e a qualidade desses recursos.

O capital social permite acesso às demais formas de capital e o capital econômico termina por assumir uma característica principal ao permitir o acesso aos recursos econômicos que permitem o indivíduo acessar as demais formas de capital mediante a consulta a especialistas e pessoas cultas que lhe influenciem em seu capital cultural, como também, a possibilidade de associar-se a instituições que lhe valorizem as credenciais pessoais nessa sociedade.

Assim a posição que o indivíduo possui na sociedade está intrinsecamente relacionada com os poderes e recursos que possui, estes recursos e poderes são tratado por 
capital, capital que podem ser econômico (renda, salário, bens), cultural (título diplomas que atestam os conhecimentos e saberes que o indivíduo possui), social (relações) e simbólico (prestígio).

Observa-se portanto que o privilégio ou o não privilégio que um indivíduo possui na sociedade é resultado da relação entre a composição e volume dos capitais que possui adquiridos ou incorporados no decorrer de sua vida que definirão o seu habitus (sistema de disposição de cultura).

A aplicação desses conceitos em relação a estruturação da dicotomia entre masculino e feminino Bourdieu (2002) afirma que simbolicamente o poder impõe significações que mascaram as relações perpetuando as relações de poder constituídas inclusive no pensamento e na concepção de mundo. Se formos relacionar a estrutura social e à constituição histórica dos cursos de Direito no Brasil onde houve a prevalência de homens desde o início, significaria apontar que essa estrutura de dominação masculina possivelmente se perpetraria nessa área no Brasil.

Contudo, é justamente essa perpetuação que será contraposta nesse estudo buscando visualizar se o fenômeno da feminização já alcançou a carreira da magistratura no Estado de Goiás.

Dessa forma, tendo a magistratura como foco de análise, observa-se que mesmo juridicamente garantida a igualdade de acesso por meio de concurso público à carreira da magistratura (BRASIL 1988), existem, como vistos, uma série de determinantes sociais que inscrevem na pessoa e nas instituições, determinada construção adstrita ao gênero que pode interferir na construção da carreira dos magistrados e magistradas.

Uma outra forma de manifestação da dominação masculina, serão vislumbradas às barreiras invisibilizadas relacionadas ao gênero, tendo em vista o ingresso da mulher em uma categoria profissional consolidada e tradicionalmente dominada por homens e a sua tentativa de condução no sentido de galgar posições mais elevadas dentro dessa carreira, o que pode se denominado como "teto de vidro" (SCHREIBER, 1979, apud. GROVER, 2015).

O termo "teto de vidro" foi primeiramente utilizado por Marianne Schreiber uma empresária da Hewlett\& Packard em uma conferência do Instituto das Mulheres para a Liberdade de Imprensa, como parte de seu discurso sobre as discrepâncias entre as políticas de promoção da mulher e as reais oportunidades de ação. (GROVER, 2015)

Da mesma forma, o termo "teto de vidro" também foi utilizado por Gay Grant em 1984 para significar uma barreira de acesso invisível de mulheres a postos superiores de 
comando, assim, as mulheres conseguem visualizar as posições de comando mas não acessálas. Grant destacava que havia espaço, havia oferta de acesso, contudo, este, ao final era negado. (GROVER, 2015)

David Cotter (apud. GROVER, 2015) estabeleceu quatro características que ao serem atendidas levam a concluir que se estabelece em determinada profissão o "teto de vidro",são elas: a) A diferença de gênero não é explicada por outras características relevantes para a execução do trabalho; b) a diferença de gênero é maior em níveis mais altos do que em níveis mais baixos da hierarquia profissional; c) a desigualdade de gênero acontece nas formas de acesso aos mais altos níveis hierárquicos não apenas em proporções desses cargos; d) A diferença de gênero aumenta ao longo do tempo da carreira;

\section{A carreira da magistratura.}

A carreira de magistrada é possível mediante a realização de concurso público conforme dispõe o artigo 93, I, da Constituição Federal de 1988, segundo redação atualizada pela EC n⿳ 45/2004, que diz “[...] o ingresso na carreira ocorrerá mediante concurso público de provas e títulos, [...] exigindo-se do bacharel em direito, no mínimo, três anos de atividade jurídica e obedecendo-se, nas nomeações, à ordem de classificação”. (BRASIL, 1988)

O ingresso na carreira que se dá pela função de juíza substituta,que segue-se para o exercício de juíza titular, e, por fim, desembargadora, cuja nomeação obedece a ordem de classificação no concurso.

Observados apenas o tempo de faculdade e de obrigatório exercício de prática jurídica, são, em regra, cinco anos de faculdade e mínimo de três anos de prática jurídica, para cumprir os requisitos legais. A partir daí, segue-se um tempo indeterminado de estudos para a aprovação no concurso da carreira. Na sequência, será obedecida a ordem de classificação no concurso e de vagas disponíveis no tribunal para preenchimento.

A nomeação ou o ingresso no cargo das juízas nos tribunais estaduais como o de Goiás obedece a distribuição territorial do estado que sãogeograficamente distribuídos em circunscrições - comarcas e distritos (Artigo $2^{\circ}$, GOIÁS, 1981), que abrigam fóruns, juizados e varas, organizados em entrância inicial, intermediária e final, no sentido de proximidade do 
interior até a capital (entrância final) onde está localizado o Tribunal de Justiça do Estado.(BRASIL, 1988)

O Código de Organização Judiciária do Estado de Goiás estabelece outros critérios para a investidura no cargo segundo o artigo 99, tais como idade mínima de vinte e um anos e máxima de quarenta e cinco ou cinqüenta para funcionários públicos efetivos. (GOIÁS, 1981)

A progressão na carreira da magistratura está prevista tanto na Constituição Federal quanto na Lei Complementar nº 35 de 1979 - Lei Orgânica da Magistratura Nacional. Estão previstas duas formas de promoção, por antiguidade e por merecimento. Respectivamente, em razão do tempo de exercício da função e por mérito nas prestações da atividade jurisdicional indicado por lista tríplice.

A previsão que consta no artigo $n^{\circ} 93$, II que a promoção acontecerá de entrância em entrância de acordo com a promoção e o merecimento. (BRASIL, 1988)

Para ser promovido por merecimento é necessário no mínimo dois anos de exercício em uma mesma entrância bem como o juiz compor a primeira quinta parte da lista de antiguidade desta entrância. Necessária também a apuração pelos critérios de produtividade e presteza no exercício da função, bem como, possuir freqüência e bom aproveitamento em cursos de aperfeiçoamento. (Artigo 93, II, “b”, “c”, BRASIL, 1988)

Torna-se obrigatória a promoção de juízes que figurarem por três vezes consecutivas na lista de merecimento ou cinco vezes de forma alternativa. (Artigo 93, II, "a", BRASIL, 1988)

Quanto a promoção por antiguidade será promovido sempre o magistrado mais antigo, todavia, este poderá ser recusado em razão do voto fundamentado de dois terços dos membros, garantida a ampla defesa. (Artigo 93, II, “d”, BRASIL, 1988)

A mesma forma de promoção será adotada para o ingresso dos magistrados no Tribunal (Artigo 93, III, BRASIL, 1988)

O Tribunal de Justiça do Estado de Goiás foi inaugurado em $1^{\circ}$ de maio de 1874 , contudo, constam em registros do período joanino (1808-1821), assim, perfaz 141 anos de existência. (MATHIAS, 2009)

Em 1873,a Relação de Goiás teve os seus primeiros desembargadores nomeados Adriano Manoel Soares, Luiz José de Medeiros, Joaquim de Azevedo Monteiro, José Ascenço da Costa Ferreira e Elias Pinto de Carvalho (Covem, 2010, p. 01). 
Em análise à composição judiciária do Estado de Goiás no ano de 2015 as informações disponibilizadas no site do Tribunal de Justiça do Estado podem ser reunidas da seguinte forma:

Na entrância inicial existem ao todo 102 vagas, destas 67 estão preenchidas. De acordo com o preenchimento a maioria das vagas está preenchida por mulheres em uma leve diferença de uma pessoa, assim, existem 35 mulheres (52,2\%) e 34 homens (47,8\%).(GOIÁS, 2015)

Na entrância intermediária existem 173 vagas, destas $110 \quad(63,6 \%)$ estão preenchidas por homens e $63(36,4 \%)$ preenchida por mulheres.(GOIÁS, 2015)

$\mathrm{Na}$ entrância final (Goiânia) existem 110 vagas, sendo que uma delas não está preenchida. Destas, $60(64,5 \%)$ são ocupadas por homens e $26(35,5 \%)$ ocupadas por mulheres.(GOIÁS, 2015)

O último grau de ascensão na carreira estadual é ocupado pelos desembargadores membros do Tribunal de Justiça com sede em Goiânia composto atualmente por 166 funções desempenhadas ao todo por 39 desembargadores. Destes 31 (79,5\%) são homens e 8 (20,5\%) são mulheres.(GOIÁS, 2015)

Abaixo visualizaremos com maiores detalhes as intersecções de gênero e magistratura no Estado de Goiás.

Se pudermos reunir todos esses dados em tabelas comparativas, elas ficarão assim dispostas:

Distribuição por Gênero da Magistratura Goiana(Julho/2015)

\begin{tabular}{|c|c|c|c|c|}
\hline & $\begin{array}{c}\text { Entrância } \\
\text { Inicial }\end{array}$ & $\begin{array}{c}\text { Entrância } \\
\text { Intermediária }\end{array}$ & $\begin{array}{c}\text { Entrância } \\
\text { Final }\end{array}$ & $\begin{array}{c}\text { Tribunal de } \\
\text { Justiça }\end{array}$ \\
\hline Total & 84 & 173 & 101 & 39 \\
\hline Vagas & 17 & 4 & 1 & - \\
\hline Mulheres & $35(52,2 \%)$ & $63(36,4 \%)$ & $26(35,5 \%)$ & $8(20,5 \%)$ \\
\hline Homens & $34(47,8 \%)$. & $110(63,6 \%)$ & $74(64,5 \%)$ & $31(79,5 \%)$ \\
\hline
\end{tabular}

Distribuição de Magistrados por Gênero nos Juizados Especiais (Julho/2015)

\begin{tabular}{|c|c|c|c|c|}
\hline & $\begin{array}{c}\text { Entrância } \\
\text { Inicial }\end{array}$ & $\begin{array}{c}\text { Entrância } \\
\text { Intermediária }\end{array}$ & Entrância Final & $\begin{array}{c}\text { Totalização } \\
\text { dos } \\
\text { Juizados }\end{array}$ \\
\hline
\end{tabular}




\begin{tabular}{|c|c|c|c|c|}
\hline & & & & \\
\hline $\begin{array}{c}\text { Total de cada } \\
\text { Entrância }\end{array}$ & 11 & 52 & 19 & 82 \\
\hline $\begin{array}{c}\text { Juizados } \\
\text { Vagos }\end{array}$ & $3(27,3 \%)$ & $2(3,8 \%)$ & - & $6,1 \%$ \\
\hline Mulheres & $2(18,2 \%)$ & $17(32,7 \%)$ & $7(36,8 \%)$ & $26(31,7 \%)$ \\
\hline Homens & $6(54,5 \%)$. & $33(63,5 \%)$ & $12(63,2 \%)$ & $51(62,2 \%)$ \\
\hline
\end{tabular}

Contrariando Sadek (2006) quanto à realidade nacional, no Estado de Goiás, não são em sua maioria mulheres que estão à frente dos Juizados Especiais, nesse segmento de atuação da magistratura os homens também predominam em uma faixa preponderante de $62,2 \%$ de todas as entrâncias contra a participação feminina que se restringe a apenas 31,7\%. Observe-se porém que esta configurava uma realidade nacional a quase dez anos atrás, mesmo assim, não houve mudanças quanto ao panorama goiano.

Distribuição de Desembargadores por Gênero e Hierarquia de funções no Tribunal de Justiça do Estado de Goiás (Biênio 2015 a 2017)

\begin{tabular}{|c|c|c|c|}
\hline & $\begin{array}{c}\text { Hierarquia de } \\
\text { funções }\end{array}$ & Mulheres & Homens \\
\hline Funções & & - & $1(100 \%)$ \\
\hline Presidente & & - & $1(100 \%)$ \\
\hline Vice-presidente & & - & $1(100 \%)$ \\
\hline Corregedor-Geral de Justiça & Presidente & - & $1(100 \%)$ \\
\hline Plenário & Membros & $8(20,5 \%)$ & $31(79,5 \%)$ \\
\hline Corte Especial & Presidente & - & $1(100 \%)$ \\
& Membros & $2(11,8 \%)$ & $15(88,2 \%)$ \\
\hline $1^{a}$ Seção Cível & Presidente & - & $9(100 \%)$ \\
& Membros & $3(25 \%)$ & $1(100 \%)$ \\
\hline $2^{a}$ Seção Cível & Presidente & - & $9(75 \%)$ \\
\hline $1^{a}$ Câmara Cível & Membros & $3(25 \%)$ & - \\
& Presidente & $1(100 \%)$ & $1(100 \%)$ \\
\hline $2^{a}$ Câmara Cível & Membros & $2(50 \%)$ & - \\
\hline
\end{tabular}


A Presença Da Mulher Na Magistratura Do Estado De Goiás

\begin{tabular}{|c|c|c|c|}
\hline & Membros & - & $4(100 \%)$ \\
\hline $3^{a}$ Câmara Cível & $\begin{array}{l}\text { Presidente } \\
\text { Membros }\end{array}$ & $\begin{array}{c}- \\
1(25 \%)\end{array}$ & $\begin{array}{l}1(100 \%) \\
3(75 \%)\end{array}$ \\
\hline $4^{a}$ Câmara Cível & $\begin{array}{l}\text { Presidente } \\
\text { Membros }\end{array}$ & $\begin{array}{c}- \\
2(50 \%)\end{array}$ & $\begin{array}{l}1(100 \%) \\
2(50 \%)\end{array}$ \\
\hline $5^{a}$ Câmara Cível & $\begin{array}{l}\text { Presidente } \\
\text { Membros }\end{array}$ & - & $\begin{array}{l}1(100 \%) \\
4(100 \%)\end{array}$ \\
\hline Seção Criminal & $\begin{array}{l}\text { Presidente } \\
\text { Membros }\end{array}$ & $\begin{array}{c}- \\
2(20 \%)\end{array}$ & $\begin{array}{l}1(100 \%) \\
8(80 \%)\end{array}$ \\
\hline $1^{a}$ Câmara Criminal & $\begin{array}{l}\text { Presidente } \\
\text { Membros }\end{array}$ & $\begin{array}{c}- \\
1(20 \%)\end{array}$ & $\begin{array}{l}1(100 \%) \\
4(80 \%)\end{array}$ \\
\hline $2^{a}$ Câmara Criminal & $\begin{array}{l}\text { Presidente } \\
\text { Membros }\end{array}$ & $\begin{array}{l}1(100 \%) \\
1(20 \%)\end{array}$ & $\begin{array}{c}- \\
4(80 \%)\end{array}$ \\
\hline $\begin{array}{c}\text { Conselho Superior da } \\
\text { Magistratura }\end{array}$ & $\begin{array}{l}\text { Presidente } \\
\text { Membros }\end{array}$ & $\begin{array}{c}- \\
2(28,5 \%)\end{array}$ & $\begin{array}{l}1(100 \%) \\
5(71,5 \%)\end{array}$ \\
\hline $\begin{array}{c}\text { Comissão de Regimento e } \\
\text { Organização Judiciária }\end{array}$ & $\begin{array}{l}\text { Presidente } \\
\text { Membros }\end{array}$ & $\begin{array}{c}- \\
1(14,3 \%)\end{array}$ & $\begin{array}{l}1(100 \%) \\
6(85,7 \%)\end{array}$ \\
\hline $\begin{array}{c}\text { Comissão de Jurisprudência e } \\
\text { Documentação }\end{array}$ & $\begin{array}{l}\text { Presidente } \\
\text { Membros }\end{array}$ & $\begin{array}{l}1(100 \%) \\
2(28,5 \%)\end{array}$ & $\begin{array}{c}- \\
5(71,5 \%)\end{array}$ \\
\hline $\begin{array}{c}\text { Comissão de Seleção e } \\
\text { Treinamento }\end{array}$ & $\begin{array}{l}\text { Presidente } \\
\text { Membros }\end{array}$ & $\begin{array}{c}- \\
3(42,8 \%)\end{array}$ & $\begin{array}{l}1(100 \%) \\
4(57,2 \%)\end{array}$ \\
\hline $\begin{array}{c}\text { Comissão de Distribuição e } \\
\text { Coordenação }\end{array}$ & $\begin{array}{l}\text { Presidente } \\
\text { Membros }\end{array}$ & $\begin{array}{c}- \\
1(33,4 \%)\end{array}$ & $\begin{array}{l}1(100 \%) \\
2(66,6 \%)\end{array}$ \\
\hline Comissão de Informatização & $\begin{array}{l}\text { Presidente } \\
\text { Membros }\end{array}$ & $\begin{array}{l}1(100 \%) \\
2(28,6 \%)\end{array}$ & $\begin{array}{c}- \\
5(71,4 \%)\end{array}$ \\
\hline $\begin{array}{c}\text { Diretoria da Revista Goiana } \\
\text { de Jurisprudência }\end{array}$ & $\begin{array}{l}\text { Presidente } \\
\text { Total de } \\
\text { Membros }\end{array}$ & - & $\begin{array}{l}1(100 \%) \\
3(100 \%)\end{array}$ \\
\hline $\begin{array}{l}\text { Escola Superior de } \\
\text { Magistratura }\end{array}$ & $\begin{array}{c}\text { Diretor } \\
\text { (desembargador) }\end{array}$ & - & $1(100 \%)$ \\
\hline & Membros: & & \\
\hline
\end{tabular}




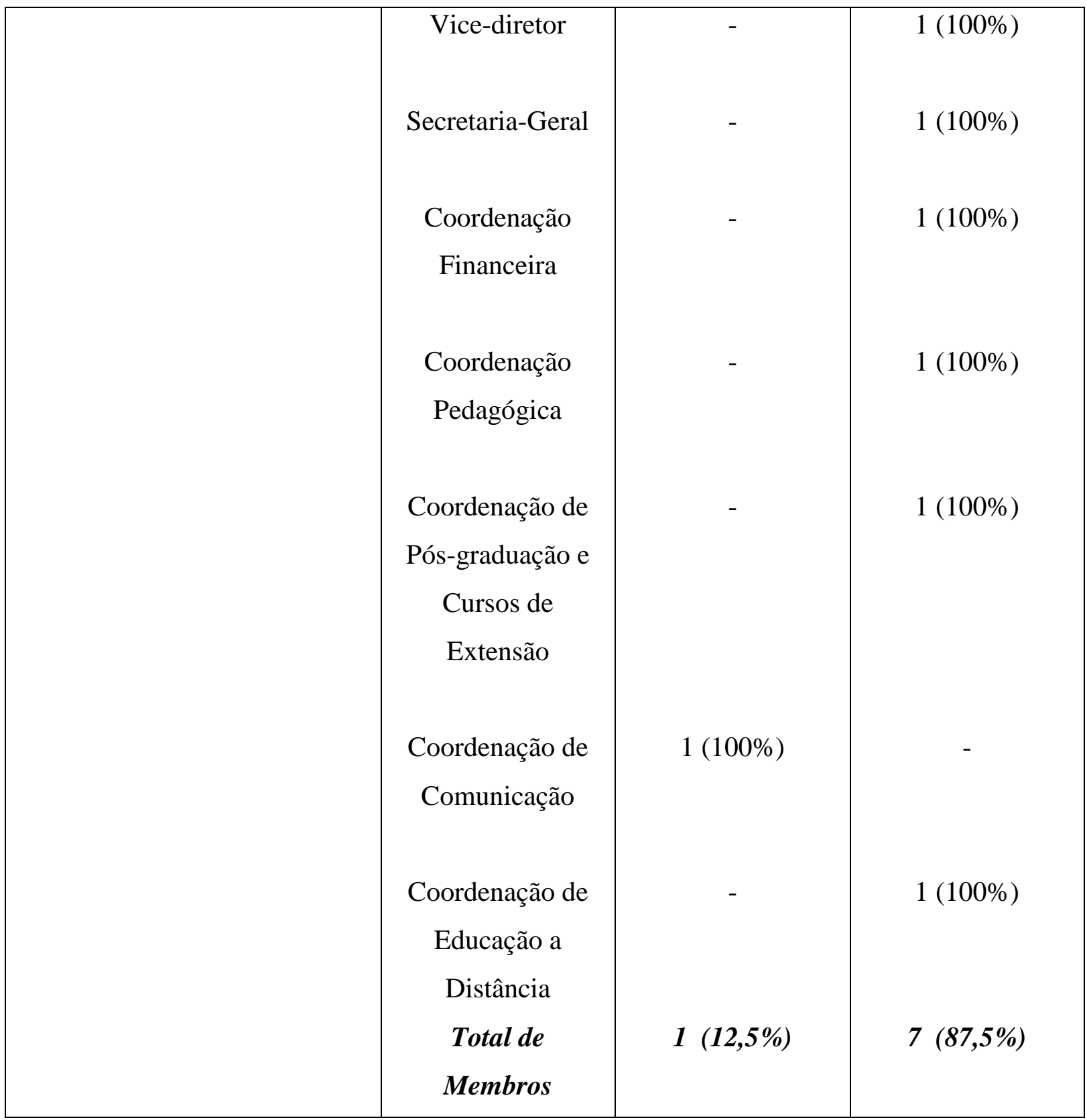

Quanto ao Tribunal de Justiça além de analisar a distribuição de funções aos desembargadores, na sequência pode-se observar a distribuição de gênero em cada uma desses segmentos.

Em nenhuma das análise foi possível localizar a presença da mulher com uma participação percentual superior a do homem. Pode-se portanto afirmar que o perfil majoritário da magistratura goiana é masculino.

Como pode ser observado na tabela, inclusive a composição da Escola Superior de Magistratura do Estado de Goiás que situa-se na área da Educação, ela é dirigida por um desembargador, os demais membros em funções de coordenação são juízes e, dentre eles, que 
ao todo são oito pessoas, apenas uma é mulher, perfazendo uma relação de $12,5 \%$ para $87,5 \%$ de homens.

Saindo um pouco da esfera estadual com o intuito de demonstrar a regularidade dos condicionantes de gênero atuantes na magistratura goiana que asseveram a caracterização preponderantemente masculina deste Tribunal, pontua-se que em 13 de julho de 2015 a Associação dos Magistrados do Estado de Goiás publicou matéria sobre a possibilidade de indicação dos nomes de dois desembargadores goianos para a composição da lista tríplice, da qual um magistrado será escolhido pela Chefe do Poder Executivo Nacional, a Presidenta da República Dilma Rousseff, para compor o Superior Tribunal de Justiça (STJ), um estágio superior na progressão da carreira da magistratura que supera a esfera estadual para atuação na esfera nacional. (ASMEGO, 2015)

Pode-se realizar um paralelo com a realidade nacional mensurada em 2014 pelo Conselho Nacional de Justiça que constatou que existem 16.812 magistrados no país e destes, 10.796 (64\%) responderam ao Censo da Magistratura Nacional. O Censo aferiu que $64 \%$ dos magistrados brasileiros são do sexo masculino, chegando a representar nos tribunais superiores uma maioria de $82 \%$ dos ministros. (CNJ, 2014)

Outros dados complementares à esta pesquisa revelam que o perfil majoritário dos magistrados são homens, brancos $(84,5 \%)$, possuem 45 anos de idade em média, iniciaram a sua carreira aos 31,6 anos para homens (30,7 anos para as mulheres), 80\% deles são casados ou encontram-se em união estável, $76 \%$ possuem filhos e cumprem jornada de trabalho na magistratura de 9 horas e 18 minutos, e quanto à formação, 63\% são pós-graduados . (CNJ, 2014)

O perfil predominantemente demonstrado no Poder Judiciário do Estado de Goiás corrobora o que Bruschini (2000) afirma sobre a manutenção do modelo do patriarcado, ou ainda, a manutenção do padrão de masculinidade hegemônica (Bourdieu, 2001) que segue a realidade nacional em índices muito próximos.

Bonelli (2008) afirma que a feminização, ou seja, a ampliação da participação das mulheres geralmente acontece quando os homens se retiram daquela ocupação, nesse sentido, observa-se e a predominância do homens não sugere uma evasão desses homens da carreira da magistratura. 


\section{Considerações finais.}

Considerando o presente estudo pode-se afirmar que a realidade encontrada revela um perfil essencialmente masculino na composição da magistratura do Poder Judiciário do Estado de Goiás.

Padrão que se repete absoluto em todas a entrâncias da organização do judiciário estatal, seja na justiça comum, nos juizados especiais ou ainda no Tribunal de Justiça.

A hipótese ventilada sobre a possibilidade de ocorrência do fenômeno da feminização não foi verificada nesta realidade.

Constata-se a manutenção de um perfil predominantemente masculino.

Pontua-se que além dessa notória maioria, a posição hierárquica distribuída entre as funções exercidas no Tribunal de Justiça, são igualmente ocupadas por homens. Das 21 atribuições de presidência ou diretoria de câmara, de comissão, de diretoria ou de escola, apenas 6 são exercidas por mulheres.

Pode-se afirmar então, que a distribuição de gênero por número total de espaços ocupados e a distribuição de gênero por hierarquia de função dentro do Poder Judiciário Estadual de Goiás é horizontal e verticalmente dominado por homens.

\section{REFERÊNCIAS BIBLIOGRÁFICAS}

ASMEGO. Associação dos Magistrados do Estado de Goiás. Desembargadores Carlos Alberto França e Luiz Cláudio Veiga Braga são inscritos em seleção para ministro do STJ. (Notícia) Disponível em: < http://asmego.org.br/2015/07/13/desembargadores-carlos-albertofranca-e-luiz-claudio-veiga-braga-sao-inscritos-em-processo-para-ministro-do-stj/ >. Acessado em: 14.jul.2015.

BARBALHO, Rennê M. (2008), A feminização das carreiras jurídicas e seus Reflexos no profissionalismo. São Carlos, UFSCar, tese de doutorado.

BONELLI, Maria da Gloria et al. Profissionalização por gênero em escritórios paulistas de advocacia. Tempo Social. São Paulo, v. 20, n. 1, p. 265-290, 2008. 
BONELLI, Maria da Gloria. Carreiras Jurídicas e vida privada: interseções entre trabalho e família. Anais $37^{\circ}$ ANPOCS, 2013. Disponível em: $<$ http://www.anpocs.org/portal/index.php?option=com_docman\&task=doc_view\&gid=8639\& Itemid=459 >. Acesso em: 10.jul.2015.

BOURDIEU, Pierre. A gênese dos conceitos de habitus e campo. In: - O poder simbólico. $4^{\mathrm{a}}$ ed. Rio de Janeiro: Bertrand do Brasil, 2001. (p. 59-73)

BOURDIEU, Pierre. Escritos de Educação. 5o edição. Petrópolis, RJ: Vozes. 2003.

BOURDIEU, P. O capital social - notas provisórias. In: CATANI, A. \& NOGUEIRA, M. A. (Orgs.) Escritos de Educação.Petrópoles: Vozes, 1998.

BOURDIEU, P. A dominação masculina. Rio de Janeiro: Bertrand Brasil, 2002.

BRASIL. Constituição Federal do Brasil (1988). Disponível em: $<$ http://www.planalto.gov.br/ccivil_03/constituicao/constituicao.htm>. Acesso em: 27.mai.2015.

BRASIL. Lei Complementar $n^{\circ} .35$ de 14 de março de 1979. Lei Orgânica da Magistratura Nacional. Disponível em: 〈http://www.planalto.gov.br/ccivil_03/leis/lcp/lcp35.htm>. Acesso em: 27.mai.2015.

BRUSCHINI, Cristina \& LOMBARDI, Maria Rosa. "A bi-polaridade do trabalhofeminino no Brasil: o emprego doméstico e as "novas ocupações"'. Cadernos de Pesquisa da Fundação Carlos Chagas, São Paulo, p. 67-104, 2000.

BRUSCHINI, C. Trabalho e Gênero no Brasil nos últimos dez anos. Disponível em:http://www.scielo.br/pdf/cp/v37n132/a0337132.pdf Acessado em: 22.mai.2015.

BRUSCHINI, C. Trabalho Feminino: trajetória de um tema, perspectivas para o futuro. Revista Estudos Feministas, p. 17-31, n.1, 1994. 
COVEM, Eliani. Marco histórico do Poder Judiciário goiano. Goiânia: 2010. Disponível em: <http://www.tjgo.jus.br/bw/wp-content/uploads/2010/05/artigo-historia-do-tjgo-136->. Acesso em 26 de março de 2014.

CNJ, Conselho Nacional de Justiça. Censo do Judiciário. (2014) Disponível em: http://s.conjur.com.br/dl/censo-magistrados-cnj.pdf>. Acesso em: 13.jul.2015.

GOIÁS. Decreto Judiciário nº 2.538/2013. Nomeia a Comissão de Editoria e Publicação para execução do projeto de reestruturação da Revista Goiana de Jurisprudência. Disponível em: $<$ http://www.tjgo.jus.br/images/docs/ccs/decreto_2538_revista.pdf >. Acessado em: 22.mai.2015.

GOIÁS. Regimento Interno do Tribunal de Justiça do Estado de Goiás. Disponível em: <http://www.tjgo.jus.br/docs/publicacoes/regimentos/regimento.pdf $>$. Acessado em: 27.mai.2015.

GOIÁS. Lei no 9.129 de 22 de dezembro de 1981. Código de Organização Judiciária do Estado de Goiás. Disponível em: <http://www.migalhas.com.br/arquivo_artigo/art2012012702.pdf>. Acessado em: 27.mai.2015.

GOIÁS. Comarcas e Juízes. Disponível em:

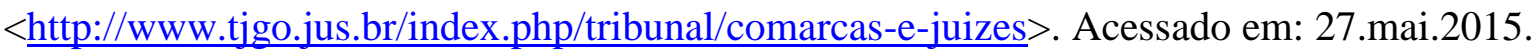

GROVER, Vijay Kumar.Glass Ceiling: A reality for women in workforce.ResearchDimensions. Vol. 2, 9 Mar. 2015. Disponível em: <http://www.researchgate.net/profile/Vijay_Grover/publication/275260348_Glass_Ceiling_A _Reality_for_Women_in_Workforce/links/553629880cf218056e92cf3b.pdf>. Acessado em: 15.jul.2015.

GUIMARÃES, Nadya; GEORGES, Isabel. A construção social de trajetórias de mando: determinantes de gênero nos percursos ocupacionais. Cadernos Pagu, 32, 2009, p.83-134. 
MATHIAS, Carlos Fernando. Notas para uma História do Judiciário no Brasil. Brasília: Fundação Alexandre de Gusmão, 2009. 440 p.

NASPOLINI, R. B. As primeiras faculdades de Direito: São Paulo e Recife. (2008) Disponível em: <http://www.egov.ufsc.br/portal/sites/default/files/anexos/29120-29138-1PB.pdf>. Acessado em: 27.abr.2003.

PISCITELLI, Adriana. (2002), "Re-criando a (categoria) mulher?”. In: ALGRANTI, Leila Mezan (org.). A prática feminista e o conceito de gênero. Campinas, Unicamp (col.Textos Didáticos, n. 48), pp. 7-42.

PISCITELLI, Adriana. Gênero: a história de um conceito. In: ALMEIDA, Heloísa e SZWAKO, José Eduardo (orgs.). Diferenças, igualdade. São Paulo: Berlendis\&Vertecchia, 2009, p. 116-48.

SADEK, M. T. Magistrados. Uma imagem em movimento. Rio de Janeiro: Editora FGV, 2006.

SCOTT, Joan. Gênero: uma categoria útil de análise histórica. Educação \& Realidade, vol. 20, no 2, 1995, p. 71-99. 